Cancer: A Story of Stem Cells and Evolution

Authors:

Submitted:

Published:

Volume:

Issue:

Keywords:

DOI:
Roland Mertelsmann

25. February 2015

26. February 2015

2

2

cancer, stem cells, evolution, Reading List English 10.17160/josha.2.2.20 


\title{
Cancer: A Story of Stem Cells and Evolution
}

\author{
Roland Mertelsmann \\ Department Medicine I, University Medical Center, Albert Ludwigs University \\ Freiburg, D-79104 Freiburg, Germany.
}

Correspondence: roland.mertelsmann@uniklinik-freiburg.de

\section{Introduction}

Cancer is an acquired genetic disease of clonal origin. Carcinogenesis and its subsequent development follow the principles of evolution, starting with a single cell with stem cell properties and a proliferative advantage, leading to clonal expansion, clonal evolution and subsequent demise by killing the host: "Evolution gone awry".

Evolution can be divided into three essential steps: 1. "Chance" or random movement of molecules allows structures to interact. 2. Molecular affinity, "Necessity" (J. Monod, Chance and Necessity: Essay on the Natural Philosophy of Modern Biology, 1970), leads to a new structure providing novel properties and function. The 3rd step of the evolutionary processes, for which I would propose the term "Synclipse", occurs, if the new constellation provides a biochemical and biological survival advantage, "survival of the fittest", in a given environmental context.

The initial event, in the context of germ line predisposing mutations/polymorphisms, reflects the cellular reaction to environmental factors: microenvironment, chemicals, radiation, viruses by altering epigenetic gene regulation. These genes of importance for proliferation, apoptosis and differentiation, are thus more prone to mutations, and after further evolution a malignant genotype is acquired. The development of these new molecular structures and functions follow the principles of evolution outlined above. These genetic alterations are the basis for the pathophysiological alterations of the malignant phenotype and are also potential targets for therapeutic strategies. The genetic analysis, whole exon and whole genome sequencing identify the genetic alterations in specific genes that frequently code for proteins targeted by small synthetic molecules. Re-sequencing in different metastasis and during the clinical course has demonstrated the ongoing evolution of cancer cells. Identification of molecular targets is the basis of modern therapeutic strategies ("Targeted Therapies"). These molecular targets, also identified by immunological techniques, can be targeted by small synthetic molecules and by immunological strategies like antibodies, immunological checkpoint inhibitors and transgenic $\mathrm{T}$ cells (Chimeric Antigen Receptor $\mathrm{T}$ Cells). While analysis of the cancer genome is increasingly becoming an integral part of clinical oncology, genetic analysis of asymptomatic persons for cancer risk as well as the incidental findings during clinical diagnostic testing of other, not cancer related prognostic genetic alterations, represent not only a clinical but also a legal and ethical challenge.

In this reading list some of the pivotal studies describing our current understanding and concepts of cancer are represented as a conceptual introduction to malignant disorders, to understanding cancer. 


\section{Historical Perspective}

On the origin of the term "stem cell".

Ramalho-Santos M , Willenbring H., Cell Stem Cell. 2007 Jun 7;1(1):35-8. doi: $10.1016 /$ j.stem.2007.05.013

"The origin of the term "stem cell," can be traced back to the late 19th century. The term stem cell originated in the context of two major embryological questions of that time: the continuity of the germ-plasm and the origin of the hematopoietic system. Theodor Boveri and Valentin Häcker used the term stem cell to describe cells committed to give rise to the germline. In parallel, Artur Pappenheim, Alexander Maximow, Ernst Neumann, and others used it to describe a proposed progenitor of the blood system. The original meanings of the term stem cell, rather than being historical relics, continue to capture important aspects of the biology of stem cells as we see them today."

These concepts led Theodor Boveri in th early 20th century to a novel concept of cancer, using somewhat different terminology then we use today, predicting molecular alterations a a perquisite for the malignant phenotype.

Cancer genetics: from Boveri and Mendel to microarrays

Balmain A ., Nat Rev Cancer. 2001 Oct;1(1):77-82.

doi: $\underline{10.1038 / 35094086}$

\section{Cancer Stem Cells and Plasticity}

Cancer stem cells: mirage or reality?

Gupta PB, Chaffer CL, Weinberg RA., Nat Med. 2009 Sep;15(9):1010-2. doi: $\underline{10.1038 / \mathrm{nm} 0909-1010}$

Cancer stem cells (CSCs) have been the focus of a broad range of research, with some controversy regarding their existence. It appears, that the CSC is not a fixed phenotype but a functional state of a cancer cell. Studies of the epithelial-mesenchymal transition (EMT) demonstrate the phenotypical plasticity between stem cells and their more differentiated derivatives. Thus cancer cells are a "moving target", which is of importance for therapeutic strategies.

Poised chromatin at the ZEB1 promoter enables breast cancer cell plasticity and enhances tumorigenicity.

Chaffer CL, Marjanovic ND, Lee T, Bell G, Kleer CG, Reinhardt F, D'Alessio AC, Young RA, Weinberg RA., Cell. 2013 Jul 3;154(1):61-74.

doi: $\underline{10.1016 / j . c e l l .2013 .06 .005}$ 
"The recent discovery that normal and neoplastic epithelial cells re-enter the stem cell state raised the intriguing possibility that the aggressiveness of carcinomas derives not from their existing content of cancer stem cells (CSCs) but from their proclivity to generate new CSCs from non-CSC populations. Here, we demonstrate that non-CSCs of human basal breast cancers are plastic cell populations that readily switch from a non-CSC to CSC state. The observed cell plasticity is dependent on ZEB1, a key regulator of the epithelial-mesenchymal transition. We find that plastic non-CSCs maintain the ZEB1 promoter in a bivalent chromatin configuration, enabling them to respond readily to microenvironmental signals, such as TGF $\beta$. In response, the ZEB1 promoter converts from a bivalent to active chromatin configuration, ZEB1 transcription increases, and non-CSCs subsequently enter the CSC state. Our findings support a dynamic model in which interconversions between low and high tumorigenic states occur frequently, thereby increasing tumorigenic and malignant potential".

\section{Random Mutations and Aging}

Cancer etiology. Variation in cancer risk among tissues can be explained by the number of stem cell divisions.

Tomasetti C, Vogelstein B., Science. 2015 Jan 2;347(6217):78-81. doi: $\underline{10.1126 / \text { science. } 1260825}$

"Some tissue types give rise to human cancers millions of times more often than other tissue types. Although this has been recognized for more than a century, it has never been explained. Here, we show that the lifetime risk of cancers of many different types is strongly correlated $(0.81)$ with the total number of divisions of the normal self-renewing cells maintaining that tissue's homeostasis. These results suggest that only a third of thevariation in cancer risk among tissues is attributable to environmental factors or inherited predispositions. The majority is due to "bad luck," that is, random mutations arising during DNA replication in normal, noncancerous stem cells. This is important not only for understanding the disease but also for designing strategies to limit the mortality it causes."

Clonal hematopoiesis and blood-cancer risk inferred from blood DNA sequence

Genovese G , Kähler AK, Handsaker RE, Lindberg J, Rose SA, Bakhoum SF, Chambert K, Mick E, Neale BM, Fromer M, Purcell SM, Svantesson O, Landén M,Höglund M, Lehmann S, Gabriel SB, Moran JL, Lander ES, Sullivan PF, Sklar P, Grönberg H, Hultman CM, McCarroll SA., N Engl J Med. 2014 Dec 25;371(26): 2477-87.

doi: $10.1056 /$ NEJMoa1409405

"Cancers arise from multiple acquired mutations, which presumably occur over many years. Early stages in cancer development might be present years before cancers become clinically apparent. Clonal hematopoiesis with somatic mutations is readily detected by means of DNA sequencing, is increasingly common as people age, and is associated with increased risks of hematologic cancer and death. A subset of the 
genes that are mutated in patients with myeloid cancers is frequently mutated in apparently healthy persons; these mutations may represent characteristic early events in the development of hematologic cancers."

Age-related clonal hematopoiesis associated with adverse outcomes.

Jaiswal S, Fontanillas P, Flannick J, Manning A, Grauman PV, Mar BG, Lindsley RC, Mermel CH, Burtt N, Chavez A, Higgins JM, Moltchanov V, Kuo FC, Kluk MJ, Henderson B, Kinnunen L, Koistinen HA, Ladenvall C, Getz G, Correa A, Banahan BF, Gabriel S, Kathiresan S, Stringham HM, McCarthy MI, Boehnke M, Tuomilehto J, Haiman C, Groop L, Atzmon G, Wilson JG, Neuberg D, Altshuler D, Ebert BL., N Engl J Med. 2014 Dec 25;371(26):2488-98.

doi: $10.1056 /$ NEJMoa1408617

"Age-related clonal hematopoiesis is a common condition that is associated with increases in the risk of hematologic cancer and in all-cause mortality, with the latter possibly due to an increased risk of cardiovascular disease."

This association might suggest between clonal alterations in hematopoiesis and damage in other organs.

Clone wars--the emergence of neoplastic blood-cell clones with aging.

Abkowitz JL., N Engl J Med. 2014 Dec 25;371(26):2523-5.

doi: $10.1056 / \mathrm{NEJMe} 1412902$

\section{Clonal Evolution}

Genetic variegation of clonal architecture and propagating cells in leukaemia.

Anderson K, Lutz C, van Delft FW, Bateman CM, Guo Y, Colman SM, Kempski H, Moorman AV, Titley I, Swansbury J, Kearney L, Enver T, Greaves M. Nature. 2011 Jan 20;469(7330):356-61.

doi: $\underline{10.1038 / \text { nature09650 }}$

"Clonal architecture is dynamic and is subject to change in the lead-up to a diagnosis and in relapse. Leukaemia propagating cells, assayed by serial transplantation in $\mathrm{NOD/SCID} \mathrm{IL2R \gamma (null)} \mathrm{mice,} \mathrm{are} \mathrm{also} \mathrm{genetically} \mathrm{variegated,} \mathrm{mirroring} \mathrm{subclonal} \mathrm{pat-}$ terns, and vary in competitive regenerative capacity in vivo. These data have implications for cancer genomics and for the targeted therapy of cancer." 
Clonal architecture of secondary acute myeloid leukemia.

Walter MJ, Shen D, Ding L, Shao J, Koboldt DC, Chen K, Larson DE, McLellan MD, Dooling D, Abbott R, Fulton R, Magrini V, Schmidt H, Kalicki-Veizer J,O'Laughlin M, Fan X, Grillot M, Witowski S, Heath S, Frater JL, Eades W, Tomasson M, Westervelt P, DiPersio JF, Link DC, Mardis ER, Ley TJ, Wilson RK,Graubert TA. N Engl J Med. 2012 Mar 22;366(12):1090-8.

doi: $\underline{10.1056 / \text { NEJMoa1106968 }}$

"Nearly all the bone marrow cells in patients with myelodysplastic syndromes and secondary AML are clonally derived. Genetic evolution of secondary AML is a dynamic process shaped by multiple cycles of mutation acquisition and clonal selection. Recurrent gene mutations are found in both founding clones and daughter subclones."

Intratumor heterogeneity and branched evolution revealed by multiregion sequencing.

Gerlinger M, Rowan AJ, Horswell S, Larkin J, Endesfelder D, Gronroos E, Martinez P, Matthews N, Stewart A, Tarpey P, Varela I, Phillimore B, Begum S,McDonald NQ, Butler A, Jones D, Raine K, Latimer C, Santos CR, Nohadani M, Eklund AC, Spencer-Dene B, Clark G, Pickering L, Stamp G, Gore M, Szallasi Z,Downward J, Futreal PA, Stanton C. N Engl J Med. 2012 Mar 8;366(10):883-92. doi: $\underline{10.1056 / \text { NEJMoa1113205 }}$

"Intratumor heterogeneity can lead to underestimation of the tumor genomics landscape portrayed from single tumor-biopsy samples and may present major challenges to personalized-medicine and biomarker development. Intratumor heterogeneity, associated with heterogeneous protein function, may foster tumor adaptation and therapeutic failure through Darwinian selection."

Biological and Therapeutic Impact of Intratumor Heterogeneity in Cancer Evolution.

McGranahan N, Swanton C . Cancer Cell. 2015 Jan 12;27(1):15-26.

doi: 10.1016/j.ccell.2014.12.001

"Here, we explore the processes shaping the cancer genome, placing these within the context of tumor evolution and their impact on intratumor heterogeneity and drug development. We review evidence for constraints and contingencies to tumor evolution and highlight the clinical implications of diversity within tumors. We outline the limitations of genome-driven targeted therapies and explore future strategies, including immune and adaptive approaches, to address this therapeutic challenge." 